\title{
A Framework for Quality Assurance of Electronic Commerce Websites
}

\author{
Zain Balfagih (1), Norshidah Mohamed(2) and Murni Mahmud(2) \\ (1) Universiti Teknologi PETRONAS,(2) International Islamic University Malaysia
}

\section{Introduction}

In the last decade, electronic commerce has significantly contributed to national economic growth. This is evident in that "according to Forrester Research, the United States (US) online retail reached $\$ 175$ billion in 2007 and is projected to grow to $\$ 335$ billion by 2012". (Source: http://www.sescommerce.com/ecommerce-growth.asp; accessed 9 May 2009) And yet, although the electronic commerce market value is growing fast, there are many electronic commerce Websites that are failing and disappearing from the market (Pather et al., 2003). The success of online business will for the large part depend on the quality of electronic commerce Websites. In keeping up with the expectations of online consumers, electronic commerce retailers will continue to face to the challenges of ensuring the quality of electronic commerce Websites. Although there have been intense discussions about quality in the literature, quality dimensions of electronic commerce are not well established and recent studies indicate that more research is needed (Mohanty et al. 2007). Lohse and Spiller (1998) stated that "the nature of electronic commerce is diverse". Due to this nature, the quality of electronic commerce Websites can be viewed from several perspectives i.e. product quality, systems as product, service quality of provider, software product quality, system design, quality of the human-computer interaction (HCI) etc. (Balfagih et al, 2008). Further in analyzing the complexity of electronic commerce quality, one can apply various bodies of knowledge i.e. information systems, marketing, human-computer interaction and design (Balfagih et al, 2008). Hence, the evaluation of quality of electronic commerce Websites depends on the perspective and role of the assessor. The assessor may be an online shopper, repeat purchaser, potential consumer, electronic commerce business owner, service provider to the business owner, Web developer etc.

This chapter proposes a framework that synthesizes previous multiple perspectives. Its aim is to aid research and practice in assuring quality of electronic commerce Websites. In this section, we have presented an overview the research background. In the following section, we discuss our review of literature on models for quality of electronic commerce Websites. Subsequently, we discuss the critiques of the literature and present the gaps that emerge out of our analysis of the literature. The gaps will be the basis for our recommendation on a framework to aid research and practice in assuring quality of electronic commerce Websites. Following that, we present the concept of software quality and software quality assurance. 
Consequently, we conclude with a recommendation and the significance of proposed framework as well as future directions for research and practice.

\section{E-commerce quality models}

Much discussion in the literature has taken the view of online consumers when evaluating the quality of electronic commerce Websites (Balfagih et al, 2008). In this regard, the online consumers may evaluate the quality of the product purchased, service quality of provider, electronic commerce systems as product quality and quality of the Human-Computer Interaction (HCI) design. The concern of this section, however, is on the electronic commerce systems as product quality and quality of the Human-Computer Interaction (HCI) design that make up quality of electronic commerce Websites.

In design, the term usability is commonly used. Usability concerns with ease of use and ease of learning. Bad usability could turn-off users or customers. It has been cited that the interface design is crucial because the user will experience usability first before deciding to conduct a transaction such as buying the product (Nielsen, 1999; Nielsen, 1993). Usability is also a critical factor for a user to re-visit or to recommend an electronic commerce Website to another customer; which is critical to the overall performance of electronic commerce. Usability may also influence users in their decision to buy the product. Several elements are important for consideration in the design process of electronic commerce Websites: selection of design features, visualization of content, navigation and control, accessibility and attractiveness. Besides, attractiveness has been cited as critical in ensuring users are attracted to a particular Website and continue to transact at the Web site (Sutcliffe, 2001; Sutcliffe, 2002).

Recognizing the importance of electronic commerce systems as product quality and quality of design, several researchers grouped critical elements that make up quality of electronic commerce design into a framework or a model. In the ensuing discussion, we will discuss Rayport and Jaworski 7Cs Framework, DeLone and McLean Electronic Commerce Model, The ISO 9126 Quality Model, WebQual 4.0 Model, Palmer's Model and Stefani and Xenos Quality Model.

\subsection{Rayport and Jaworski 7Cs Framework}

Rayport and Jaworski (2001, pp. 115-117) developed the 7Cs framework in defining the quality of electronic commerce Website design from the online consumers' perspective.

- Context - The context of an electronic commerce Website defines its aesthetic and functional look-and-feel which encompasses interesting graphics, colors, design features, goals and ease of navigation.

- Content - The content in an electronic commerce Website defines all digital subject matter including text, video, audio and graphics to convey the message of the site.

- Community - This aspect refers to the communication that occurs between two users such as through e-mails or chat. This element, however, does not cover a user's experience when interacting with the Website.

- Customization - Customization refers to the electronic commerce Website's ability to tailor itself or to be tailored by each user such that a user is provided with a 
function or functions that enables him to enter personal details or customize the look of a banner.

- Communication - Communication is defined as the dialogue that occurs between the site and its users through e-mail notification, customer service request or customer messaging.

- Connection - This aspect defines the extent of formal linkages between the electronic commerce Website and other sites.

- Commerce - This covers the functions that the online consumer may use such as "shopping basket", check-out process etc.

\subsection{DeLone and McLean Electronic Commerce Model}

The DeLone and McLean Electronic Commerce Model was an updated and extended model of information systems success (DeLone and McLean, 2003). The authors argued that there were six major dimensions of electronic commerce model: system quality, information quality, service quality, use, user satisfaction, and net benefit.

- System quality - this aspect refers to the desired characteristics of an electronic commerce system. Usability, availability, reliability, adaptability and response time (e.g., download time) are examples of qualities that are valued by users of an electronic commerce system.

- Information quality - this captures the e-commerce content issue.

- Service quality - measures the overall support delivered by the service provider.

- Usage - measures everything from a visit to a Website, to navigation within the site, to information retrieval and to execution of a transaction.

- User satisfaction - this is the affective attitude towards the electronic commerce Website which can be measured by re-purchasing or re-visiting.

- Net benefits - this captures the balance of positive and negative impacts of the electronic commerce on customers, suppliers, employees, organizations, markets, industries, economies and even our societies.

Figure 1 shows the DeLone and McLean Electronic Commerce Model.

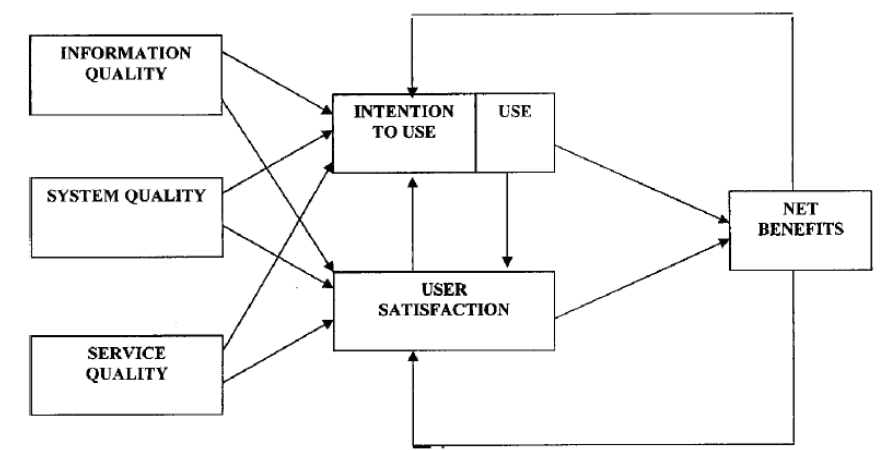

Fig. 1. DeLone and McLean Electronic Commerce Model

For each of the dimensions, DeLone and McLean (2003) suggested measures for operationalization (see Table 1). 


\begin{tabular}{|l|l|}
\hline \multicolumn{1}{|c|}{ Dimensions } & \multicolumn{1}{|c|}{ Measures } \\
\hline Systems quality & $\begin{array}{l}\text { Adaptability, availability, reliability, response time, } \\
\text { usability }\end{array}$ \\
\hline $\begin{array}{l}\text { Information } \\
\text { quality }\end{array}$ & $\begin{array}{l}\text { Completeness, ease of understanding, personalization, } \\
\text { relevance, security, service quality, assurance, empathy, } \\
\text { responsiveness }\end{array}$ \\
\hline Use & $\begin{array}{l}\text { Nature of use, navigation patterns, number of site visits, } \\
\text { number of transactions executed }\end{array}$ \\
\hline User satisfaction & Repeat purchases, repeat visits, user surveys \\
\hline Net benefits & $\begin{array}{l}\text { Cost savings, expanded markets, incremental additional } \\
\text { sales, reduced search costs, time savings }\end{array}$ \\
\hline
\end{tabular}

Table 1. DeLone and McLean Electronic Commerce Model Metrics

\subsection{The ISO 9126 Quality Model}

The ISO/IEC 9126:2001 (ISO/IEC, 2001a) is the latest revision to the international software product quality standard (Figure 2). The ISO 9126 defines quality as a set of six features and/or characteristics of a product or service that bear on its ability to satisfy stated or implied needs: functionality, reliability, usability, efficiency, maintainability and portability (ISO 9126, 2001).

- Functionality - refers to the essential purpose of the software functions.

- Reliability - reliability is defined as the capability of the system to maintain its service provision under defined conditions for defined periods of time.

- Usability - this is the set of attributes that bear on the effort needed for use, and on the individual evaluation of such use, by a stated or implied set of users. Usability comprises four quality sub-characteristic: attractiveness, learnability, understandability and operability.

- Efficiency - this defines the capability of the system to provide appropriate performance, relative to the amount of resources used and under stated conditions. Efficiency entails both conceptual and implementation difficulties.

- Reliability - the quality characteristics that refer to a set of attributes that bear on the capability of software to maintain its level of performance under stated conditions for a stated period of time.

- Maintainability and portability - also referred to as the internal factors of the ISO 9126 model that measure the quality of the backend of the system.

It has been suggested that adopting and adapting ISO 9126 for specific domains is not new and not foreign to the standard itself (Cody and Kishore, 2006). The ISO 9126 can be used as the basis for electronic commerce quality evaluation but further analysis and mapping of its characteristics and sub-characteristics to system functions/services is required (Stefani, 2008). Past researches have shown that different models that follow the ISO 9126 software standard quality model were used to assess the quality of electronic commerce Websites (ISO 9126, 2001) and (Olsina et al, 2000). 


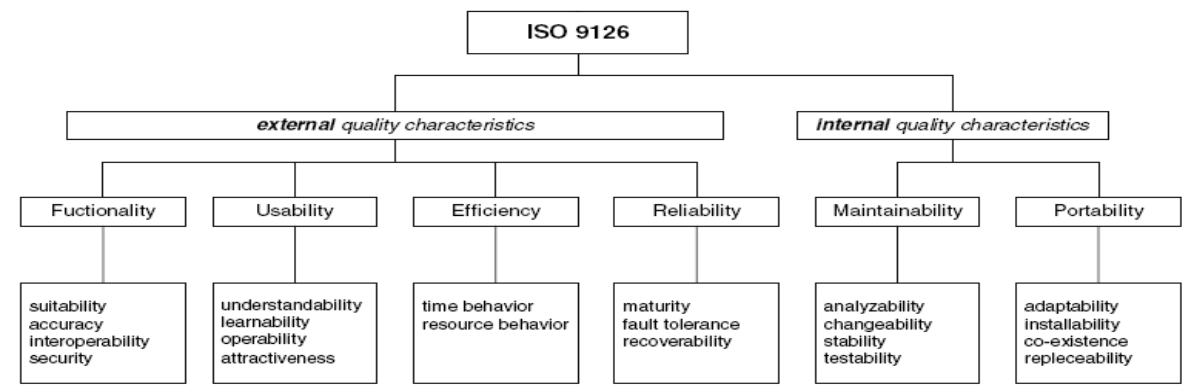

Fig. 2. ISO 9126 Quality Model

\subsection{SERVQUAL Model}

One dominant theoretical model that has emerged from the information systems and marketing literature and that perhaps can be used to assess the quality of electronic commerce Websites is the Service Quality (SERVQUAL) model (Parasuraman et al., 1988). The SERVQUAL model is an instrument that comprises 22 statements which measure the performance across five dimensions. For each statement, the expectation and the experience of a customer are determined.

- Reliability - refers to the ability to perform the promised service dependably and accurately.

- Assurance - includes competence, courtesy, credibility and security.

- Responsiveness - means the willingness to help customers and provide prompt service.

- Tangibles - includes physical facilities, equipment and appearance of personnel.

- Empathy - refers to access, communication, understanding the customer; in short the demonstration of care and individualized attention that a firm provides its customers.

Since 1988, many research efforts utilizing the SERVQUAL framework have proliferated the literature (Iwaarden and Wiele, 2003) and (Sinnapan \& Carlson, 2004). All five SERVQUAL dimensions i.e. reliability, responsiveness, assurance, empathy, and tangibles have been cited as relevant and important in Web-based environment (Cao et al, 2005).

It has been cited, however, that the SERVQUAL model has posed different problems as a measure for quality (Myerscough, 2008). The problems have been classified into conceptual and empirical (Myerscough, 2008). Conceptual problems refer to the definition of service quality as a difference or gap score between a customer's perceptions and expectations, the ambiguity of the expectation constructs, and the generality of SERVQUAL as a single measure of service quality across different industries and settings (Myerscough, 2008). Empirical problems can encompass issues like overestimated reliability, poor convergent validity, poor predictive validity, and unstable dimensionality caused by different or gap scores of each dimension in the SERVQUAL model (Park and Baek, 2007).

\subsection{WebQual 4.0}

WebQual 4.0 draws on research from three core areas: information quality, interaction and service quality, and usability (Barnes and Vidgen, 2003). WebQual is based on quality 
function deployment (QFD). The application of QFD starts with capturing the voice of "customers" using words that are meaningful to the customers. These qualities are then fed back to the customers and form the basis of an evaluation of the quality of product or a service (Barnes and Vidgen, 2003).

In WebQual, users are asked to rate target sites against each of a range of qualities using a seven-point scale. Thereafter, users will be asked to rate each of the qualities for the importance that are considered by the user to be most important in any given situation (Barnes and Vidgen, 2003). The standard WebQual 4.0 instrument contains 23 questions (see Table 2).

\begin{tabular}{|c|c|}
\hline Category & Questions \\
\hline Usability: & $\begin{array}{l}\text { 1- I find the site easy to learn to operate } \\
\text { 2- My interaction with the site is clear and understandable } \\
\text { 3- I find the site easy to navigate } \\
\text { 4- I find the site easy to use } \\
\text { 5- The site has an attractive appearance } \\
\text { 6- The design is appropriate to the type of site } \\
\text { 7- The site conveys a sense of competency } \\
\text { 8- The site creates a positive experience for me }\end{array}$ \\
\hline $\begin{array}{l}\text { Information } \\
\text { Quality: }\end{array}$ & $\begin{array}{l}\text { 9- Provides accurate information } \\
\text { 10- Provides believable information } \\
\text { 11- Provides timely information } \\
\text { 12- Provides relevant information } \\
\text { 13- Provides easy to understand information } \\
\text { 14- Provides information at the right level of detail } \\
\text { 15- presents information in appropriate format }\end{array}$ \\
\hline $\begin{array}{l}\text { Service } \\
\text { Interaction: }\end{array}$ & $\begin{array}{l}\text { 16- has a good reputation } \\
\text { 17- It feels safe to complete transactions } \\
\text { 18- My personal information feels secure. } \\
\text { 19- Creates a sense of personalization } \\
\text { 20- Conveys a sense of community } \\
\text { 21- Makes it easy to communicate with the organization } \\
\text { 22- I feel confident that goods/services will be delivered as } \\
\text { promised } \\
\text { 23-Overall view of the Web site }\end{array}$ \\
\hline
\end{tabular}

Table 2. WebQual 4.0 instruments 


\subsection{The Palmer's Model}

The Palmer's quality model is based on the close association between usability and Website design quality (see Table 3). Design quality covers easy-to-use navigation, frequent updating, minimal download times, relevance to users, high quality contents, response time and credibility (Palmer, 2002). It has been suggested that high levels of media richness is reflected in its results, with interactivity and responsiveness constructs related to Website success.

Table 3. Palmer's Metrics

\begin{tabular}{|l|l|}
\hline \multicolumn{1}{|c|}{ Constructs } & \multicolumn{1}{c|}{ Measures } \\
\hline Content Quality & Amount of information, Variety of information \\
\hline Navigation & Arrangement, sequence, Links, Layout \\
\hline Download Delay & Initial Access Speed, Speed of Display Between Pages \\
\hline Responsiveness & Feedback, FAQ \\
\hline Interactivity & Customization Interactivity \\
\hline
\end{tabular}

\subsection{The Stefani and Xenos QualityModel}

User-centred design has continuously been the focal attention for quality of electronic commerce Websites (Stefani and Xenos, 2001; Stefani, 2008). The Stefani and Xenos Quality Model provides another such evidence (see Table 4).

The model is built upon three levels and four factors. The levels were defined as high, middle and low. The high level comprises basic characteristics of electronic commerce systems such as the search engine service, ease of navigation, security and reliable transaction etc. The middle level includes services such as site map services, multilingualism, and attractive interface. The low level includes additional services and facilities aimed at improvements of user perceived usability and efficiency such as cross selling, variety of colors and graphics, etc. The four factors have been defined as functionality, reliability, usability and efficiency. Functionality covers suitability, accuracy, interoperability and security. Reliability has sub-characteristics like maturity, fault tolerance and recoverability. Usability refers to understandability, learnability and operability. Efficiency encompasses time-behavior and resource behavior.

\begin{tabular}{|l|l|}
\hline Characteristics of electronic commerce systems & \multicolumn{1}{|c|}{$\begin{array}{c}\text { Related quality } \\
\text { factors }\end{array}$} \\
\hline $\begin{array}{l}\text { Easy access to the web pages of the e-commerce } \\
\text { system }\end{array}$ & $\begin{array}{l}\text { Functionality } \\
\text { Usability } \\
\text { Efficiency }\end{array}$ \\
\hline Easy navigation & $\begin{array}{l}\text { Functionality } \\
\text { Usability }\end{array}$ \\
\hline Adaptation to user profile & $\begin{array}{l}\text { Functionality } \\
\text { Usability } \\
\text { Efficiency }\end{array}$ \\
\hline Search engine service & $\begin{array}{l}\text { Functionality } \\
\text { Usability } \\
\text { Reliability }\end{array}$ \\
\hline Easy exit - undo functions & Functionality \\
\hline
\end{tabular}




\begin{tabular}{|l|l|}
\hline Useful help service & $\begin{array}{l}\text { Functionality } \\
\text { Usability } \\
\text { Efficiency }\end{array}$ \\
\hline Electronic shopping cart & $\begin{array}{l}\text { Functionality } \\
\text { Usability }\end{array}$ \\
\hline Electronic shopping list & $\begin{array}{l}\text { Functionality } \\
\text { Usability }\end{array}$ \\
\hline Secure and reliable transactions & $\begin{array}{l}\text { Functionality } \\
\text { Reliability }\end{array}$ \\
\hline Secure protocols SET, SSL & Reliability \\
\hline $\begin{array}{l}\text { Correct and accurate information about the } \\
\text { products }\end{array}$ & Reliability \\
\hline Direct delivery of the products & $\begin{array}{l}\text { Usability } \\
\text { Efficiency }\end{array}$ \\
\hline Indisputable financial transactions & Reliability \\
\hline Recoverability of products and services & $\begin{array}{l}\text { Usability } \\
\text { Functionality }\end{array}$ \\
\hline Legitimate Website & Reliability \\
\hline
\end{tabular}

Table 4. Stefani and Xenos Quality Model

\section{Critiques of the Literature}

In the previous section, we have discussed various electronic commerce quality models such as Rayport and Jaworski 7Cs Framework, DeLone and McLean Electronic Commerce Model, The ISO 9126 Quality Model, WebQual 4.0 Model, Palmer's Model, and Stefani and Xenos Quality Model. These models were drawn from the fields of information systems, marketing, human-computer interaction and design. The researchers' focus has been on online consumers' perspective.

As evident, the literature discussed has not covered the integration between the developer's perspective and the online consumer's perspective. In ensuring all possible alternatives are taken care of during implementation of an electronic commerce system, there is a need for such integration.

Quality design of electronic commerce system does not happen by chance. Rather, it needs to be planned. The planning takes place during the software development process of the electronic commerce project between the developer and the users including potential online consumers. As an electronic commerce Website could be regarded as a piece of software, software quality and software quality assurance practices could be a reference point in ensuring the quality of electronic commerce Website. Hence, researchers and practitioners in electronic commerce would benefit from the synthesis of knowledge in software quality and software quality assurance. 


\section{Software Quality and Software Quality Assurance}

Software quality is one important factor that could determine the success or failure of the software. Software quality calls for critical attention that covers the functionality of the software to be built, cost of developing the software, schedule it takes to build the software and cost evaluation on building, implementing and maintaining it. Essentially, ensuring quality during software development process reduces the overall cost by reducing the defect correction costs which can be inherently complex especially in the late stages of the development process. The cost of low quality can amount to more than $50 \%$ of total costs of software development (Tian, 2005). Correcting defects in early stages imposes less cost than correcting them in later stages. Preventing defects from the beginning by applying appropriate quality assurance system is even more cost effective that just correcting them when they occur. In the electronic commerce context, ensuring the quality of electronic commerce Websites could help business owners to gain customers' loyalty and attract more customers. It has been stated that the quality of electronic commerce Websites plays a crucial role in customers' re-purchase intention (Zamzuri et al., 2008). Hence, in achieving repeated "winning" in the electronic commerce market, it may be worthwhile to ensure software quality of the electronic commerce systems.

Pressman and Ince (2000) defined software quality as "conformance to explicitly stated functional and performance requirements, explicitly documented development standard and implicit characteristics that are expected from the professionally developed software." Software quality concerns are on three main factors. The first factor is the functionality and performance requirements which are usually identified during planning and analysis phase of the software life cycle. The second factor is the conformance of the software to the industry or field standards. The third factor is the professionalism in developing the software by implementing good practices of software development even if it is not specified in the requirements or standards. The definition implies that software quality does not necessarily entail error-free application while it satisfies users' requirements and expectations. On the other hand, Godbole (2005) referred to software quality as meeting users' requirements in time and within budget. It has also been highlighted that user satisfaction is important in software quality (Chen, 2005).

The Institute of Electrical and Electronics Engineers (acronym: IEEE) recommends conformance to Software Quality Assurance (SQA) framework when developing a software. It defines SQA as "a planned and systematic pattern of all actions necessary to provide adequate confidence that an item or product conforms to established technical requirements. It includes a set of actions designed to evaluate the process by which the product is developed or manufactured" (IEEE, 1990). This definition indicates the different phases of quality assurance (QA) practices during a software development life cycle. However, it has been cited that the definition lacks non-technical requirements from SQA process that includes information quality, budget and time (Galin, 2003).

There are several definitions of software quality and software quality assurance in the literature. However, most of them consider testing with developing and implementing SQA plans for the software projects (Dromey, 1995; Giance, 1998). This task includes all the activities needed to ensure software quality from the beginning to the end of the project life cycle. This includes both technical and non technical activities. SWEBOK (2004) defined software quality assurance as processes that provide assurance to the software products and processes in project life cycle so that they conform to the specified requirements by 
planning, enacting and performing a set of activities that provide adequate confidence that quality is being built into the software. This definition suggests that the first part of software quality assurance is the development of SQA plan. Software quality assurance plan defines the means that will be used to ensure that the software developed for a specific product satisfies the users' requirements and is of the highest quality possible within project constraints. The major tasks included in the SQA plan are:

- Identifying quality assurance project objectives.

- Developing quality factors, quality criteria and quality metrics.

- Identifying list of the standards, practices, and conventions.

- Developing guidelines for every step of the quality assurance processes.

- Specifying the responsibilities of SQA group with the schedule of the different quality assurance activities.

- Developing reviews (design reviews and peer reviews), walkthroughs and checklists.

Another main part of the SQA is the implementation of the SQA plan. The main tasks included in this part are:

- Conducting reviews includes management reviews, design reviews, peer reviews, walkthroughs and checklists. These reviews provide early detection for analysis and design defects in the early stages before it becomes inherent in the software and more complex to be corrected in late stages.

- Conducting testing and evaluation. The IEEE (1990) defines testing as "(1) The process of operating a system or component under specified conditions, observing or recording the results and making an evaluation of some aspect of system or component. (2) The process of analyzing a software item to detect the differences between existing and required conditions (that is, bugs) and to evaluate the features of the software item." We will discuss the different types of software testing in the electronic commerce quality assurance framework section.

- Conducting verification and validation. Verification is the process that determines whether the product fulfills the project requirements or not while validation is the process of evaluating the software to ensure the compliance with software requirements.

- Conducting maintenance and monitoring for the software after production.

Laudon and Traver (2007) built upon the systems development life cycle to define the electronic commerce Website development process. They defined five phases in the process: systems analysis/planning, systems design, building the system, testing and implementation service delivery.

- Systems analysis/planning - refers to defining business objectives of the electronic commerce, system functionality and information requirements.

- Systems design - this phase describes the main components of the system and their relationships to one another.

- Building the system - this phase calls for the decisions on development of the system and implementation. Outsourcing or development in-house could be the options.

- $\quad$ Testing - Regardless the decision made on building the system, testing is required. Laudon and Traver (2007) defined three levels of required testing i.e. unit test that involves program modules, system test that covers testing the site as a whole and acceptance test that involves users of the system. 
- Implementation and maintenance - this phase covers the monitoring, adapting the site for change, improvement and correction.

Bidgoli (2002) suggested that the electronic commerce life cycle comprises problem definition and requirement analysis, feasibility study, formation of the task force, analysis, design, simulation prototyping, implementation, post-implementation audit and monitoring, site marketing and management.

\subsection{Software engineering practice in electronic commerce development}

Acknowledging the contributions of (Bidology, 2002) and (Laudon and Traver, 2007), we will apply the phases in software engineering practice recommended in sommervelli (2007) to ease the discussion on quality assurance process for electronic commerce Websites. The phases are planning, designing, implementation, testing and post-implementation. Each of the phases covers a discussion on the different quality assurance activities required for successful delivery of the electronic commerce Website.

\subsection{The planning phase}

Planning serves as a guide on how quality is to be built in and how it is to be evaluated. Quality cannot be added at the end of an electronic commerce project. Quality must be included from the early steps of a project and continuously evaluated to ensure that it is satisfactory. This is also the reason that a quality plan should be produced very early in the life of an electronic commerce project. Quality assurance plan helps to schedule quality assurance activities and define the factors that will lead to the successful completion of an electronic commerce project. A quality assurance plan is a document that contains all quality assurance activities throughout the project lifecycle including processes, procedures, standards, reviews and audits, checklists, tests, quality factors and quality metrics. The quality assurance activities in the planning phase consist of the following steps:

\section{General information}

In this step, we identify the purpose and scope of the quality assurance plan. In addition, this step provides a general system overview which includes responsible organization, system title, system environment etc. Also, the plan must identify the functional requirements and evaluation criteria of the electronic commerce project. The project goals might include marketing campaign, supporting sales activities, providing new channels of communication with the customers etc. Tasks and responsibilities are also identified in this step where the project leader, electronic commerce application development groups and the quality assurance sub-committee and their responsibilities are assigned.

Standards, practices and conventions

This section of the electronic commerce quality assurance plan identifies the standards, practices and conventions to be applied. It states how compliance with these items is to be monitored and assured. It specifies documentation standards, security standards, coding standards, payment standards etc.

Specification of requirements

In this step, we describe the entire requirements for the electronic commerce system behavior. It includes a set of use cases to represent the functional requirements of the system and specifications for the non-functional requirements. These requirements must be clear, 
complete and measurable. Considerations of non-functional requirements include among others usability, reliability, trust, interface satisfaction and information quality.

- Usability - Many prior works concerning electronic commerce systems consider usability as an important factor in electronic commerce quality (Stefani and Xenos, 2001; Palmer, 2002). Usability is achieved when all functions of an electronic commerce system are developed in a way that seeks to help the end-users by simplifying their actions (Stefani, 2008). High usability means an electronic commerce system is easy to learn and remember, efficient, visually pleasing and fun to use, and quick to recover from errors (Shaikh et al, 2001). However, electronic commerce Website usability is not easily achievable because there is no unified view on how to build a usable Website despite the number of frameworks and guidelines already advocated by industry experts and consultants (Kuan et al., 2005).

- Understandability - Feedback and Help features as well as interface and aesthetic features mark the characteristics of promoting ease in understandability of electronic commerce Website.

- Reliability - Reliability could be assessed on the basis of the electronic commerce system. In this sense, reliability encompasses security of electronic financial transactions (Stefani and Xenos, 2001). Besides, reliability in the ISO 9126 document specifies maturity, fault tolerance and recoverability. Shaikh et al. (2001) defined reliability as the ability of a system to consistently produce the same result and be able to meet or exceed the set specifications.

Reliability may also be assessed from the users' perspective of the electronic commerce services' provider. Based on SERVQUAL, reliability defines the ability of personnel rendering electronic commerce services to perform promised services dependably and accurately.

- $\quad$ Trust - The risks and their associated levels inherent in electronic commerce makes trust a critical consideration in quality assurance of electronic commerce Websites. Trust reduces the uncertainty and risks perceived by users. Consequently, trust enhances users' perception about the Website and this should lead to higher users' satisfaction with the Website (Chen, 2005). Trust is defined as the subjective probability that customers believe that an organization's underlying technology infrastructure and control mechanisms are capable of supporting transactions (Cao, et al., 2005). This definition is however, confined to trust in general and hence, may not necessarily refer to electronic commerce per se. However, perhaps, the most succinct definition of trust in relation to electronic business could be "a consumer's willingness to accept vulnerability in an online transaction based on [his] their positive expectations regarding an e-retailer's future behaviors" (Cody and Kishore, 2006).

- Interface satisfaction - Interface satisfaction measures consumers' evaluation of the Website interface design in terms of information presentation, webpage navigability, ease of use and efficiency of interaction with the Website. Chen (2005) states that interface satisfaction includes ease of use, information presentation and information time. It has been stated however, that the term structural awareness of an interface implies that the interface makes the users aware of the larger structure of the information content in the web pages in an electronic business application 
(Cody and Kishore, 2006). On the technical side, interface satisfaction may include graphics, help system, support of a foreign language and customer service (Shaikh et al., 2001; and Cox and Dale, 2002).

- Information quality - Three commonly used metrics to evaluate information quality are information accuracy, relevance, and completeness (Cao et al., 2005; Cody and Kishore, 2006). Information accuracy is the extent to which the information is accurate and the extent that it determines, among others, whether the promise is fulfilled. Information relevance refers to the extent to which the information on the Website is related to the information needs of the customers. Information completeness means that the information on the web page is available to the extent that the online consumers need it. DeLone and Mclean (2003) suggests five subcharacteristics for information quality: completeness, ease of understanding, personalization, relevance and security.

Creating test plans

After identifying the electronic commerce project requirements, we need to start planning for the testing process. A test plan is a document that describes the approach of testing activities and identifies the items to be tested, the types of tests to be performed, test schedules, reports that are to be produced, evaluation criteria, etc. (Lewis, 2004). The general outline of the test plan includes an introduction, business function, testing requirements, testing software and hardware, personnel and testing schedule. This plan will be the basis for accomplishing the testing process. At the same time, the test plan will be refined and expanded throughout the phase until we reach to the testing phase. The main objective for the testing process is to reveal the existing errors as much as possible and to ensure that the delivered electronic commerce Website meets the functional and non-functional requirements.

\subsection{The design phase}

In the electronic commerce project life cycle, this stage contains detailed definition for the system inputs, outputs, procedures, data structure, databases, Website map and structure, Website interface components etc. The design phase translates the business requirements into electronic commerce system specifications that can be used by programmers during coding (Implementation) phase. A lack of quality in the design phase can invalidate the requirement specifications identified earlier and can make the correction process difficult and costly. The major tasks of electronic commerce quality assurance in this phase include: Design

This step defines the designers' selection of a set of design attributes that should be measured at the end of the phase. There should also be procedures to evaluate the overall quality of the design process. The electronic commerce quality assurance would have a specification for approval of design standards and a guideline to ensure that they are followed and that all the electronic commerce project requirements are allocated to the project components. A checklist during the design phase is recommended in helping designers improve design quality. The general principles of electronic commerce Website design practice should cover at least the following but not limited to:

- The Website is easy to navigate and easy to learn.

- It is compatible with the different Web browsers, screen resolutions and color settings. 
- $\quad$ There is "About us" section in the Website.

- All the pages are not too lengthy.

- There are easy ways to get customers comments and feedbacks.

- There is a date stamp with the Website information.

- There is a search facility in the Website.

- There are no broken links, missing images or graphics.

- There are no scripting and HTML coding errors that may cause a page to not display.

- There are no slow page downloads due to excessive use of graphics or long pages.

- $\quad$ There is no sound "auto play".

Verification and validation

Validation is the set of quality assurance activities that ensures that the right functions are performed while verification is the set of quality assurance activities that ensures the correct performance of these specified functions. In other words, validation checks whether a function needed by the customers are present in the electronic commerce system while verification checks the conformance of the electronic commerce system to its specifications that we identified earlier in the planning phase. Among the activities included in verification and validation process are acceptance testing, ensuring the traceability of identified requirements in the planning phase, ensuring the feasibility of achieving functional and performance requirements, ensuring the feasibility of user requirements etc. Verification and validation are continuous processes to ensure that requirements identified in the previous phase are accomplished in the current phase. Therefore, this step is required in all the phases except the very early phase.

Expansion of the testing plan

In this step, test plans are explained in more detail. Test cases for the electronic commerce system are created in this phase. The test cases include test data, test script or guidelines, test input and the expected results from each test case. In this step, we need to conduct a system test for the resulted design to demonstrate whether the system meets the original requirements of the project or not. Regardless, this step may not require the complete preparation of test plans, test procedures, test tools, types of required tests etc.

\subsection{The implementation (coding) phase}

In this phase, developers implement the outcomes of the design phase by building the electronic commerce Website and other applications associated to it. Generally, the basis of good programming entails the application of defined set programming standards. The assumption is that development is done in-house provided resources are abundance.

However, where resources could be a significant constraint, an alternative to in-house development is outsourcing. Outsourcing the development of electronic commerce Website could be faster and cheaper. On the other hand, outsourcing limits flexibility in handling changes and diminishes ownership and control. It has been cited however that most of medium and large-size organizations prefer to build their Websites from scratch using commercial site-building software with some opting for hard coding (Cassidy, 2001).

Coding

In this step, quality assurance team checks whether developers have followed a proper use of programming language and defined standards or not. They have to ensure that the codes comply to coding standards of the language style. Checks are performed to determine 
whether the codes fulfil the design specification for the functionality, data structures and user interface.

Verification and validation

In this step, we verify the fulfilment of the design specification developed in the design phase using code walkthroughs, peer code review, checklists, inspections and formal verifications.

Completing the testing plans

By the end of this phase, all the components of the testing plans should be completed. All the test cases must be described in detail including the objectives, inputs, expected outputs, and testing procedure. Also, the testing tasks must be assigned to the respective testing team members by the end of this phase including other details such as test time and required resources.

\subsection{The testing phase}

This phase implements the test plans generated so far. The testing process itself is one of the main activities of quality assurance in electronic commerce development life cycle. The priority of this phase is to have all tests run according to test plans and procedures. Other priority is ensuring that test reports are complete and correct and that test results are documented properly. The essential tasks of quality assurance in this phase include:

Testing

During this phase, tests are carried out by running the test cases according to the already established test procedures.

- Usability evaluation - This activity characterizes the conduct to determine the extent to which the electronic commerce Website is understood, easy to learn, easy to operate, easy to navigate and is attractive to the online consumers.

- Unit testing - This is the process of testing each part of the electronic commerce Website individually to ensure that it performs its assigned function accordingly.

- Acceptance testing - This refers to the testing of the electronic commerce Website with respect to users' defined needs, requirements and expectations. The aim is to determine whether or not the electronic commerce Website satisfies the acceptance criteria.

- Compatibility testing - It measures how well the electronic commerce Website pages could be displayed on different browsers, different browser version, different resolutions, different operating systems and different machines.

- Integration testing - This test is performed to find defects in the interfaces and in the interactions between different components of the electronic commerce Website.

- Regression testing - This refers to a re-testing of a previously tested Website after a modification is performed on the Website to ensure that defects have not been introduced or uncovered in unchanged areas of the electronic commerce Website.

- System testing - This is the process of testing the whole Website after completing all of the components to verify that it meets specified requirements.

- $\quad$ Stress testing - This set of tests evaluates the electronic commerce Website or its associated components at or beyond the limits of its specified requirements.

- Testability Testing - This measures the ease of testing a component in the electronic commerce Website or a specific functionality so that test plans and scripts could be executed properly. 
- Validation testing - Validation is the term used to refer to the act of verifying that the HTML code in a file meets the DTD (Document Type Definition) for any particular version of HTML.

Evaluation and Re-testing

This process entails that every error discovered during the test process ought to be documented in detail for evaluation and correction. These documents will be used again in the regression testing to compare the results before and after correcting the defects. In addition, we need to evaluate the testing process itself at the end of this phase. This evaluation will help to improve the testing process in future. Metrics that can be used in evaluating the testing process are number of the test cases, detected errors, number of defects uncovered in the testing, cost of testing, and average cost of locating a defect.

\subsection{Development and post-deployment phase}

Although the main objective of electronic commerce quality assurance practice is to detect defects before publishing the Website, it is practically impossible to create an error-free electronic commerce Website and system. Therefore, we need continuous quality improvement standards to keep up with the changes of the electronic commerce Website. The basis for changes would typically emerge out of customers' inputs and feedbacks.

Monitoring

In this step, we first collect the run time data about the successes and failures in electronic commerce Website operations. The data should represent the functionality, performance, usability, reliability, and other quality factors of the operations. Then, we analyze the collected data in order to detect any available defects in the Website. Another great source for the defects is customers' feedback about; in particular their experiences in browsing the Website. The availability of channels to be in contact with the customers in any electronic commerce Website as a customer support service is highly recommended. After this, the developers should start to analyze and correct the failures that had occurred or been reported.

Upgrade

The electronic commerce Website components can be improved to provide better performance, more functionality, higher in content quality, or greater usability. Most of the electronic commerce Websites would expand with additional services to their original Websites from time to time in fulfilling and exceeding customers' satisfaction, needs and expectations.

\section{Recommendation and Conclusion}

The success of online business will, for the large part, depend on the quality of electronic commerce Websites. Our review of past researches suggests models of quality assurance of electronic commerce Websites that are fragmented and distinct in that they were confined to the respective perspectives of assessors and specific concerns.

This work has been built based on our earlier work that had been drawn from the fields of information systems, marketing, human-computer interaction and design. The limitation of the prior work was that the literature in these fields confined discussions within the online consumers' perspective as evaluators. The assessment is made on electronic commerce Website with the view of systems as a product. 
This chapter extends our previous work with a proposal of a framework that synthesizes these previous multiple perspectives with the developers' perspective. In particular, our emphasis in this chapter is that, in order to arrive at quality electronic commerce Website as a final system product, one must adhere to a set of quality assurance processes during the electronic commerce life cycle. This form the basic building blocks for the end product. In this regard, we adopt the view of software quality, software quality assurance and software engineering. Figure 3 shows our proposed synthesis as a framework for quality assurance of electronic commerce Websites.

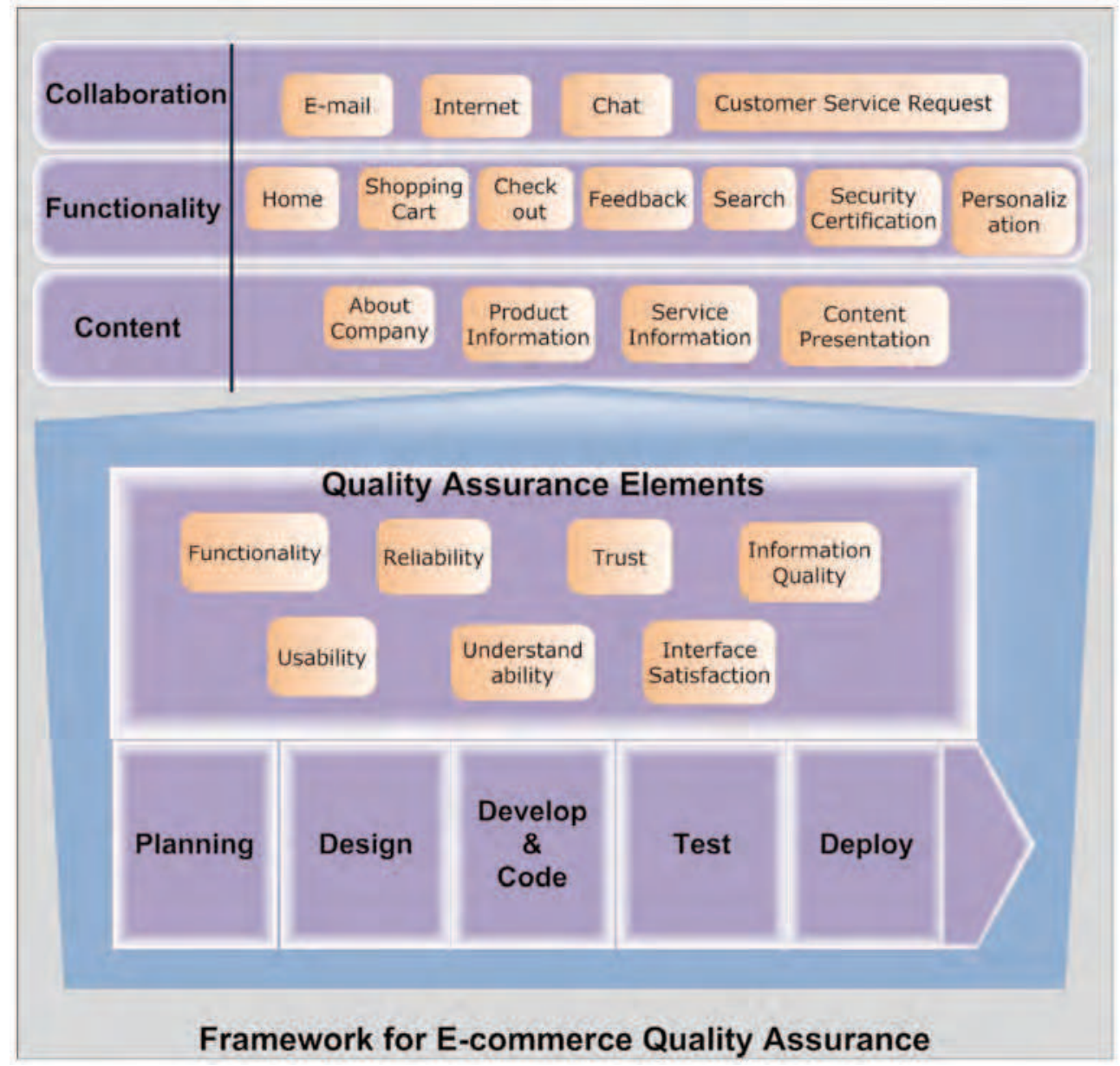

Fig. 3. A Framework for Quality Assurance of Electronic Commerce Websites

Quality of electronic commerce Websites is an important factor in attracting potential consumers, encouraging first-time purchases and retaining repeat purchases. It has been emphasized that the quality of electronic commerce Websites is an important factor for consumers in selecting the most preferred Website that ultimately results in more revenue 
for the Websites (Lohse and Spiller, 1999; Ngai, 2003 and Carnero, 2005). The proposed framework provides a bird's eye view to aid discussions in research practice toward ensuring the quality of electronic commerce Websites. One consideration for future research areas could be to validate the elements of quality from the various perspectives.

\section{References}

Balfagih Z., Mohamed N., Mahmud M., (2008). Search of a model for evaluating the quality of e-commerce websites. In proceedings of ITSIM'08, Malaysia.

Barnes S. J., Vidgen R., (2003). Measuring Web Site Quality Improvements, A Case Study Of The Forum Measuring Web site quality improvements: a case study of the forum on strategic management knowledge exchange, Industrial Management \& Data Systems, 103(5). pp. 297-309.

Bidgoli H., (2002). Electronic Commerce: Principles and Practice. Academic Press, USA.

Cao M., Zhang Q., Seydel J., (2005). B2C E-Commerce Web Site Quality, An Empirical Examination, Industrial Management \& Data Systems, 105(5): pp. 645-661.

Carnero M.C., (2005). Selection of diagnostic techniques and instrumentation in a predictive maintenance program: a case study, Decision Support Systems 38 (4) pp. 539- 555.

Cassidy A., (2001). A Practical Guide to Planning for E-Business Success, How to E-Enable Your Enterprise. St. Lucie Press. USA.

Chen R., (2005). Modeling of User Acceptance of Consumer E-Commerce Website, SpringerVerlag Berlin Heidelberg

Cody A. E., Kishore R., (2006). An Extension of the UTAUT Model with E-Quality, Trust, and Satisfaction Constructs, Proceedings of the 2006 ACM SIGMIS CPR conference on computer personnel research, California, pp. 82 - 89.

Cox J., Dale B.G., (2002). Key Quality Factors In Web Site Design And Use, An Examination, International Journal of Quality\& Reliability Management, Vol 19 No 7, pp. 862888.

DeLone W. H., McLean E. R., (2003). The DeLone and McLean Model of Information Systems Success, A Ten-Year Update, Journal of Management Information Systems, 19(4). pp. 9-30.

Dromey, R. G. (1995). A model for software product quality, IEEE Trans. on Software Engineering, Vol. 21, No. 2, Feburary. pp. 146-162.

Galin D., (2003). Software Quality Assurance: From Theory to Implementation. Addison Wesely, England.

Giance, F. P., (1998). Customer oriented software quality assurance, Upper Saddle River, NJ: Prentic Hall.

Godbole N. S., (2005). Software Quality Assurance: Principles and Practices. Slpha Sciences, Oxford U.K.

IEEE Standard Glassory of Software Terminology 610.12-1990, (1990), IEEE Computer Society, USA.

ISO/IEC 9126, (2001). Software Product Evaluation-Quality Characteristics and Guidelines for the user, International Organization for Standardization, Geneva.

Iwaarden J., Wiele T., (2003). Applying SERVQUAL to Web Sites: an exploratory study, International Journal of Quality \& Reliability Management, 20 (8). pp. 919-935. 
Kelly B., Vidgen R., (2005). A quality framework for web site quality: user satisfaction and quality assurance. Special interest tracks and posters of the 14th international conference on World Wide Web, Chiba, Japan, pp. 930 - 931

Kuan H. H., Bock G., Vathanophas V., (2005). Comparing The Effects Of Usability On Customer Conversion And Retention At E-Commerce Websites, Proceedings of the 38th Hawaii International Conference on System Sciences. IEEE.

Laudon, K. C. and Traver, C. G. (2007). E-commerce: Business, Technology and Society. Pearson Education International, New Jersey.

Lewis W. E., (2004). Software Testing and continous Quality Improvment. Auerbach Publications, USA.

Lin F. Huarng J. K., Chen Y., Lin S. M., (2004). Quality Evaluation of Web Services, IEEE, pp. 1-6. International Conference on E-Commerce Technology for Dynamic E-Business, pp. 226-233.

Lohse G.L., Spiller P., (1999). Internet retail store design: how the user interface influences traffic and sales, Journal of Computer Mediated Communication 5

Mohanty, R. P., Seth, D., Mukadam, S. (2007). Quality Dimensions of E-Commerce and their Implications. Total Quality Management \& Business Excellence, vol $18(3,4)$ pp. 219-247.

Myerscough M., (2008). Concerns About Servqual's Underlying Dimensions, www.iacis.org/iis/2002_iis/PDF\%20Files/Myerscough.pdf (accessed on Mar 26 2008).

Ngai E.W.T., (2003). Selection of web sites for online advertising using the AHP, Information and Management 40. pp. 233- 242.

Nielsen J., (1999). Designing web usability: The practice of simplicity. New Riders Publishing, Indianapolis, Indiana.

Nielsen J., (1993). Usability engineering. Academic Press, Boston.

Olsina L., Lafuente G., Rossi G., (2000). E-commerce Site Evaluation a Case Study, Electronic Commerce and Web Technologies, Springer, Berlin/ Heidelberg, pp. 239-252.

Palmer J. W., (2002). Web Site Usability, Design, and Performance Metrics, Information Systems Research, 13(2): pp. 151-167.

Parasuraman A., Zeithaml V.A., Berry L.L., (1988) SERVQUAL: a Multiple-Item Scale For Measuring Consumer Perceptions Of Service Quality, Journal of Retailing, 64 (1). pp. 12-40.

Park H., Baek S., (2007). Measuring Service Quality of Online Bookstores with WebQual, Human-Computer Interaction. HCI Applications and Services, Springer, Berlin/ Heidelberg, pp. 95-103.

Pather S., Erwin G., and Remenyi D., (2003). Measuring E-commerce Effectivness: A Conceptual Model. Proceedings of SAICSIT03, pp. 143-152.

Pressman R. S., Ince D., (2000). Software Engineering - A Practical Approach Eurapian Adaption. McGraw-Hill Publishing Company, UK.

Rayport, J. E. and Jaworski, B. J. (2001). E-Commerce. McGraw-Hill Higher Education, New York.

Shaikh M. A., Whittaker J. A., Al-Badi A. H., AI-Ameri A., (2001). E-Commerce Need Analysis Via Quality Function Deployment, IEEE Computer Society 
Sinnappan S., Carlson J., (2004). An examination of website quality dimensions in Australian e-retailing: a confirmatory factor analysis approach, Intelligent Information Technology, Springer, Berlin/ Heidelberg, pp. 410-418

Sommerville I. , (2007). Software Engineering 8. Addison-Wesley, 9780321313799, USA.

Stefani A., Xenos M., (2008). E-Commerce System Quality Assessment Using A Model Based On ISO 9126 And Belief Networks, Software Quality Control, 16(1): pp. 107-129.

Sutcliffe A. G., (2002). Assessing the reliability of heuristic evaluation for website attractiveness and usability, Proceedings of the 35th Hawaii International Conference on System Sciences, Honolulu: University of Hawaii, pp. 1838-1847.

Stefani A., Xenos M., (2001). A model for assessing the quality of e-commerce systems, Proceedings of the PC-HCI, 2001, pp. 105-109.

Sutcliffe A. G., (2001). Heuristic evaluation of website attractiveness and usability. in GIST Technical Report G2001,1: Proceedings: 8th Workshop on Design, Specification and Verification of Interactive Systems, Glasgow, University of Glasgow, pp. 188-199.

Tian J., (2005). Software Quality Engineering: Testing, Quality Assurance, and Quantifiable Improvment. Wiley Inter Science, Canada

Zamzuri, N.H.A. Mohamed, N. Hussein, R., (2008). Antecedents of customer satisfaction in repurchase intention in the electronic commerce environment. Proceednig of ITSim 2008, Kuala Lumpor. 


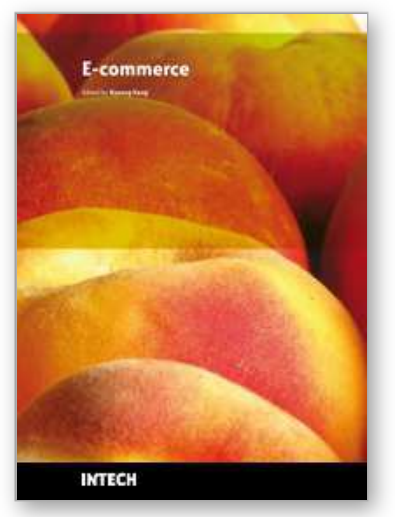

\author{
E-commerce \\ Edited by Kyeong Kang
}

ISBN 978-953-7619-98-5

Hard cover, 284 pages

Publisher InTech

Published online 01, February, 2010

Published in print edition February, 2010

E-commerce provides immense capability for connectivity through buying and selling activities all over the world. During the last two decades new concepts of business have evolved due to popularity of the Internet, providing new business opportunities for commercial organisations and they are being further influenced by user activities of newer applications of the Internet. Business transactions are made possible through a combination of secure data processing, networking technologies and interactivity functions. Business models are also subjected to continuous external forces of technological evolution, innovative solutions derived through competition, creation of legal boundaries through legislation and social change. The main purpose of this book is to provide the reader with a familiarity of the web based e-commerce environment and position them to deal confidently with a competitive global business environment. The book contains a numbers of case studies providing the reader with different perspectives in interface design, technology usage, quality measurement and performance aspects of developing web-based e-commerce.

\title{
How to reference
}

In order to correctly reference this scholarly work, feel free to copy and paste the following:

Zain Balfagih, Norshidah Mohamed and Murni Mahmud (2010). A Framework for Quality Assurance of Electronic Commerce Websites, E-commerce, Kyeong Kang (Ed.), ISBN: 978-953-7619-98-5, InTech, Available from: http://www.intechopen.com/books/e-commerce/a-framework-for-quality-assurance-ofelectronic-commerce-websites

\section{INTECH}

open science | open minds

\section{InTech Europe}

University Campus STeP Ri

Slavka Krautzeka 83/A

51000 Rijeka, Croatia

Phone: +385 (51) 770447

Fax: +385 (51) 686166

www.intechopen.com

\section{InTech China}

Unit 405, Office Block, Hotel Equatorial Shanghai

No.65, Yan An Road (West), Shanghai, 200040, China

中国上海市延安西路65号上海国际贵都大饭店办公楼405单元

Phone: +86-21-62489820

Fax: $+86-21-62489821$ 
(C) 2010 The Author(s). Licensee IntechOpen. This chapter is distributed under the terms of the Creative Commons Attribution-NonCommercialShareAlike-3.0 License, which permits use, distribution and reproduction for non-commercial purposes, provided the original is properly cited and derivative works building on this content are distributed under the same license. 